\title{
Exacerbation of hydrate agglomeration in the presence of kinetic hydrate inhibitor under high $\mathrm{pH}$ condition
}

Myungchul Park ${ }^{\mathrm{ab}}$, Younghoon Sohn ${ }^{\mathrm{a}}$, Hyunho Kimª ${ }^{\mathrm{a}}$ Ki-Heum Park ${ }^{\mathrm{a}}$, Mincheol Ryu ${ }^{\mathrm{b}}$, Yutaek Seo, ${ }^{\mathrm{a}, *}$

a Department of Naval Architecture and Ocean Engineering, RIMS, Seoul National University, Seoul 151-744, Republic of Korea

${ }^{\mathrm{b}}$ Energy System R\&D, Daewoo Shipbuilding and Marine Engineering, Siheung 15111, Republic of Korea

*Corresponding Author: Yutaek Seo, Tel: +82-2-880-7329, Email: yutaek.seo@,snu.ac.kr 


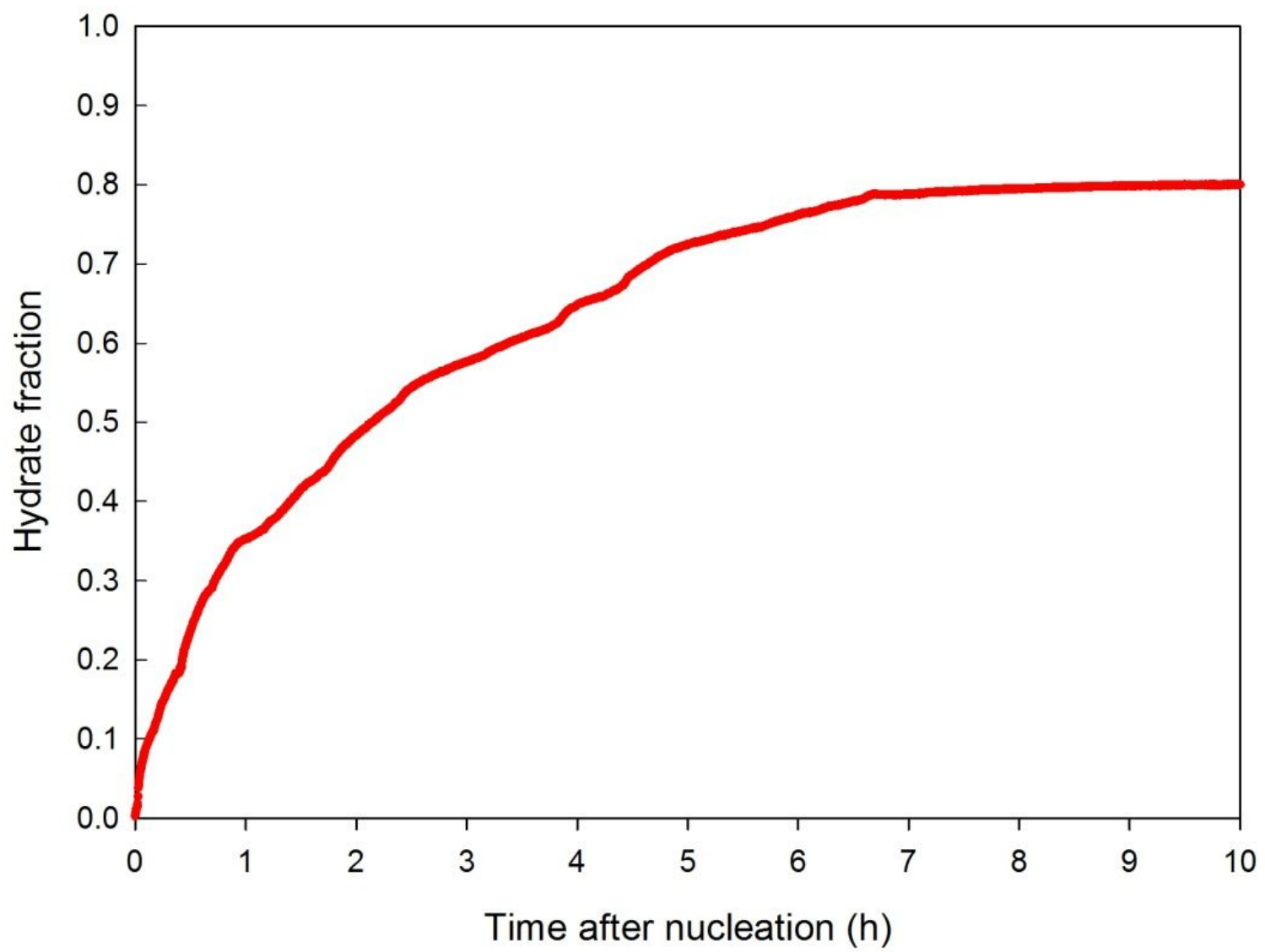

Figure S1: Hydrate fraction curves for pure water with $600 \mathrm{rpm}$ during 10 hour. 
(a)

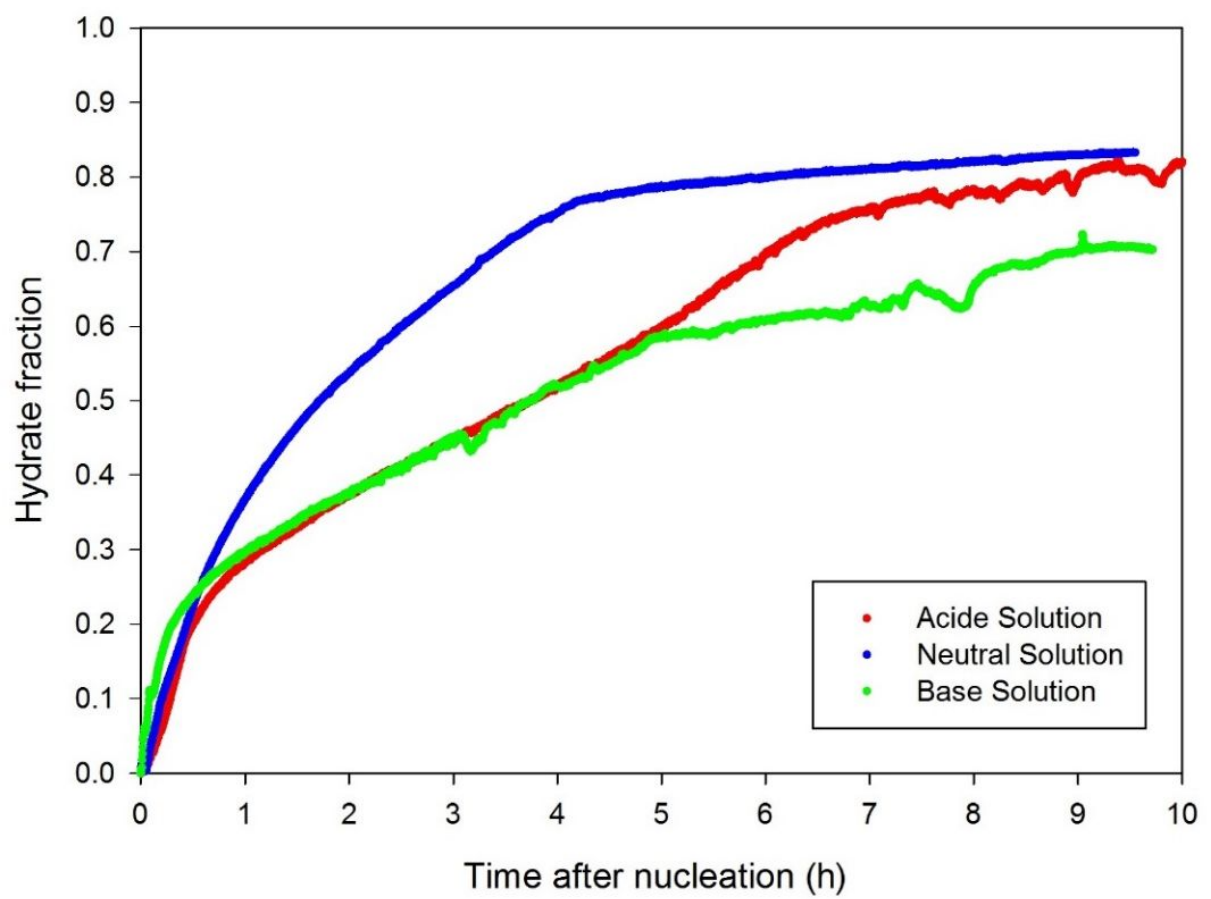

(b)

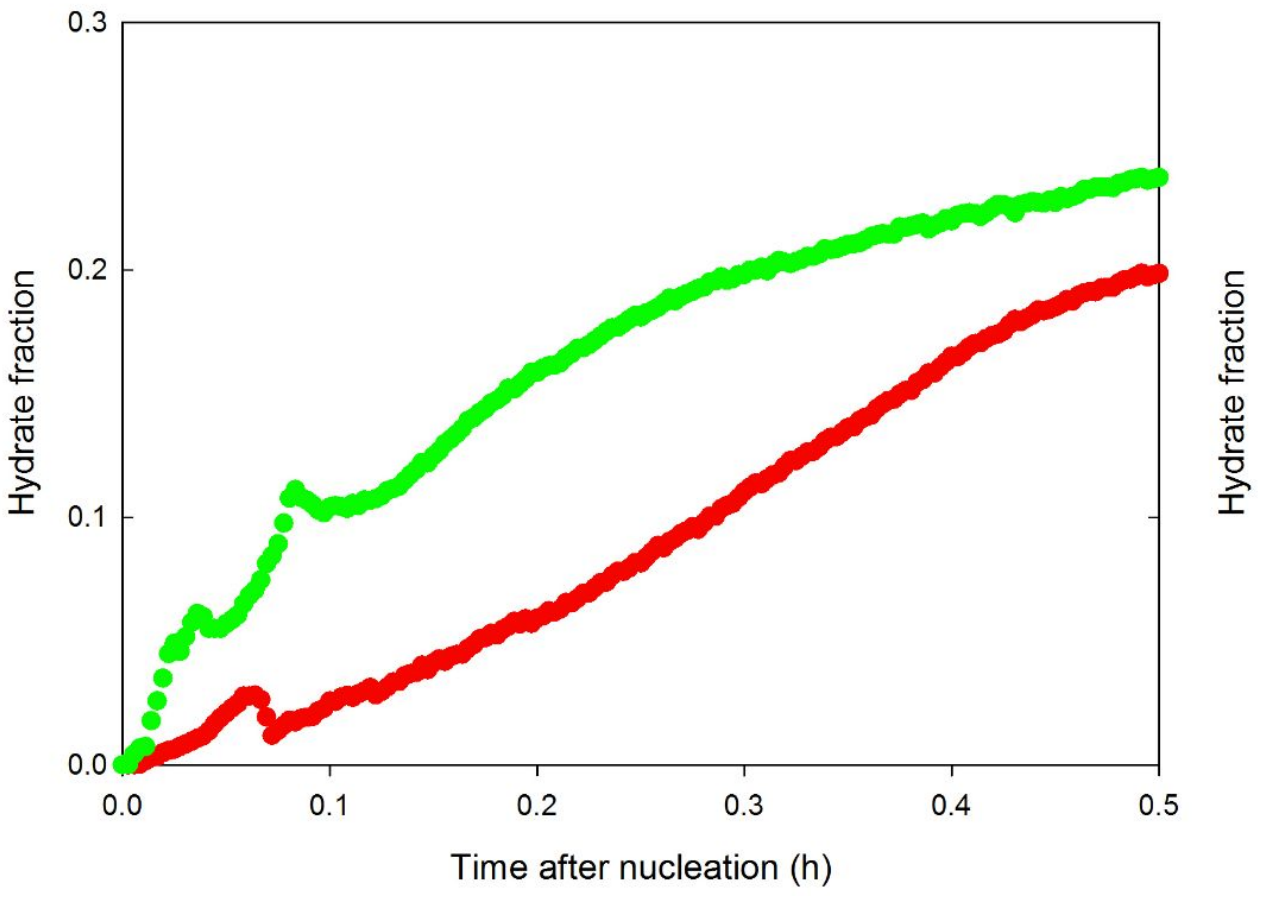

Figure S2: (a) Hydrate fraction curves for $0.5 \mathrm{wt} \%$ Luvicap solution with $600 \mathrm{rpm}$ during 10 hour. (Green line) Base solution, (Blue line) Neutral solution, (Red line) Acid solution. (b) Close-up version of Figure S2(a) during 0.5 hour. (Green line) Base solution, (Red line) Acid solution 


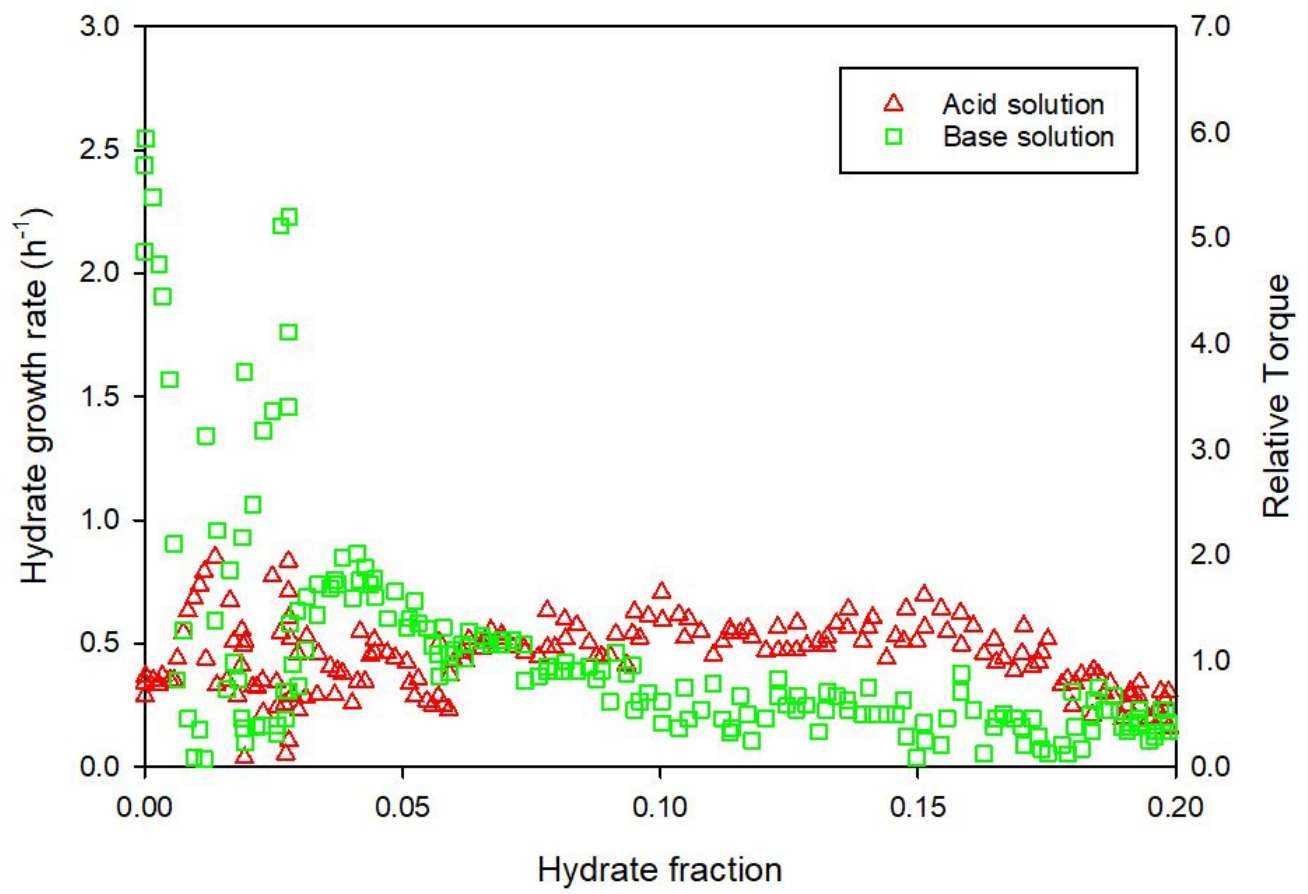

Figure S3: Changing hydrate growth rate as a function of hydrate fraction for Luvicap EG 0.5 wt $\%$ solution at $\mathrm{pH} 4.5$ and 9.5. (Close up version of Figure 4, hydrate fraction up to 0.2 )

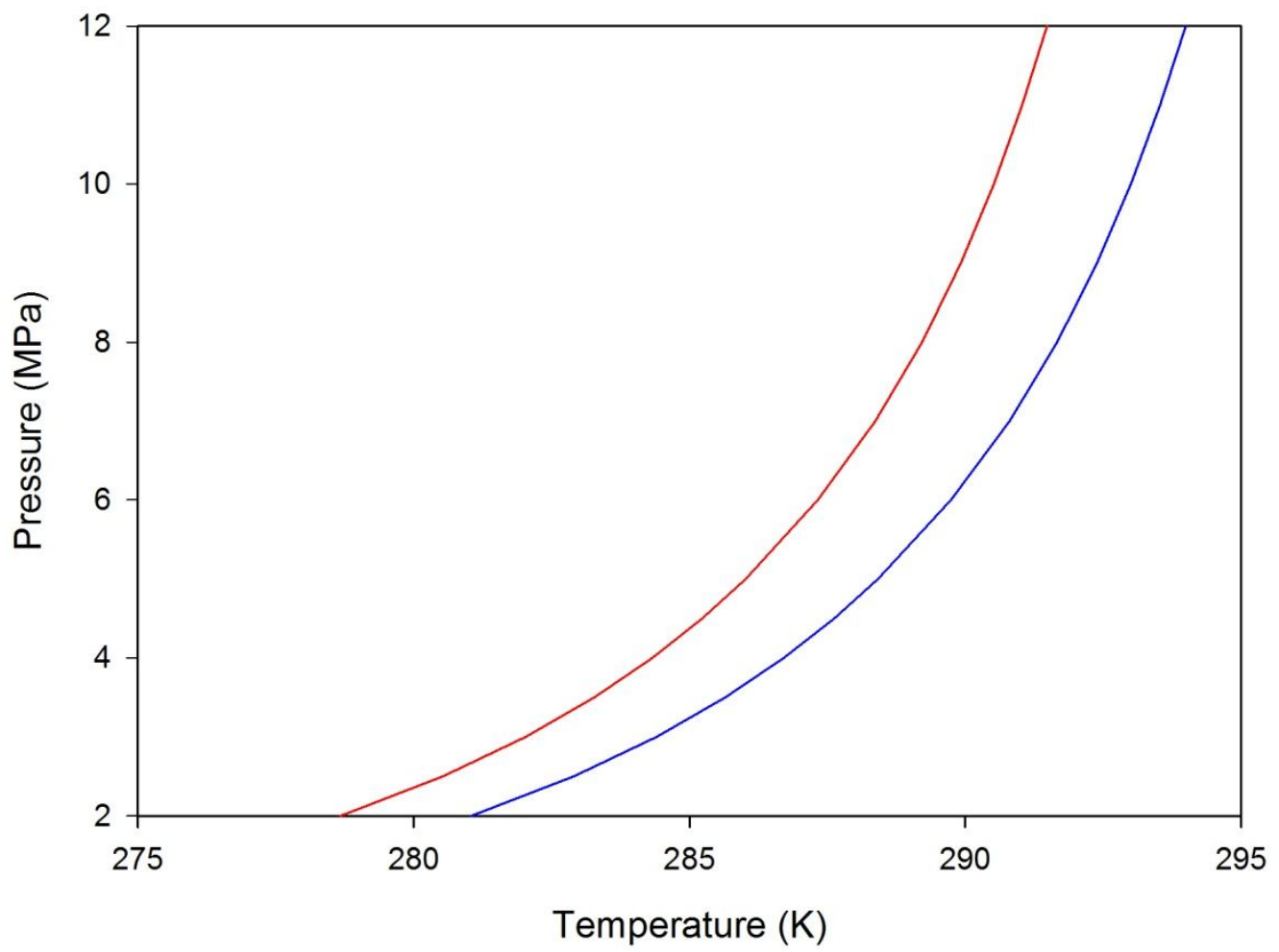

Figure S4: Hydrate Equilibrium curves in presence of pure water (Blue line) and $10 \mathrm{wt} \%$ MEG (Red Line). The curves were calculated from Multiflash 6.1. 
(a)

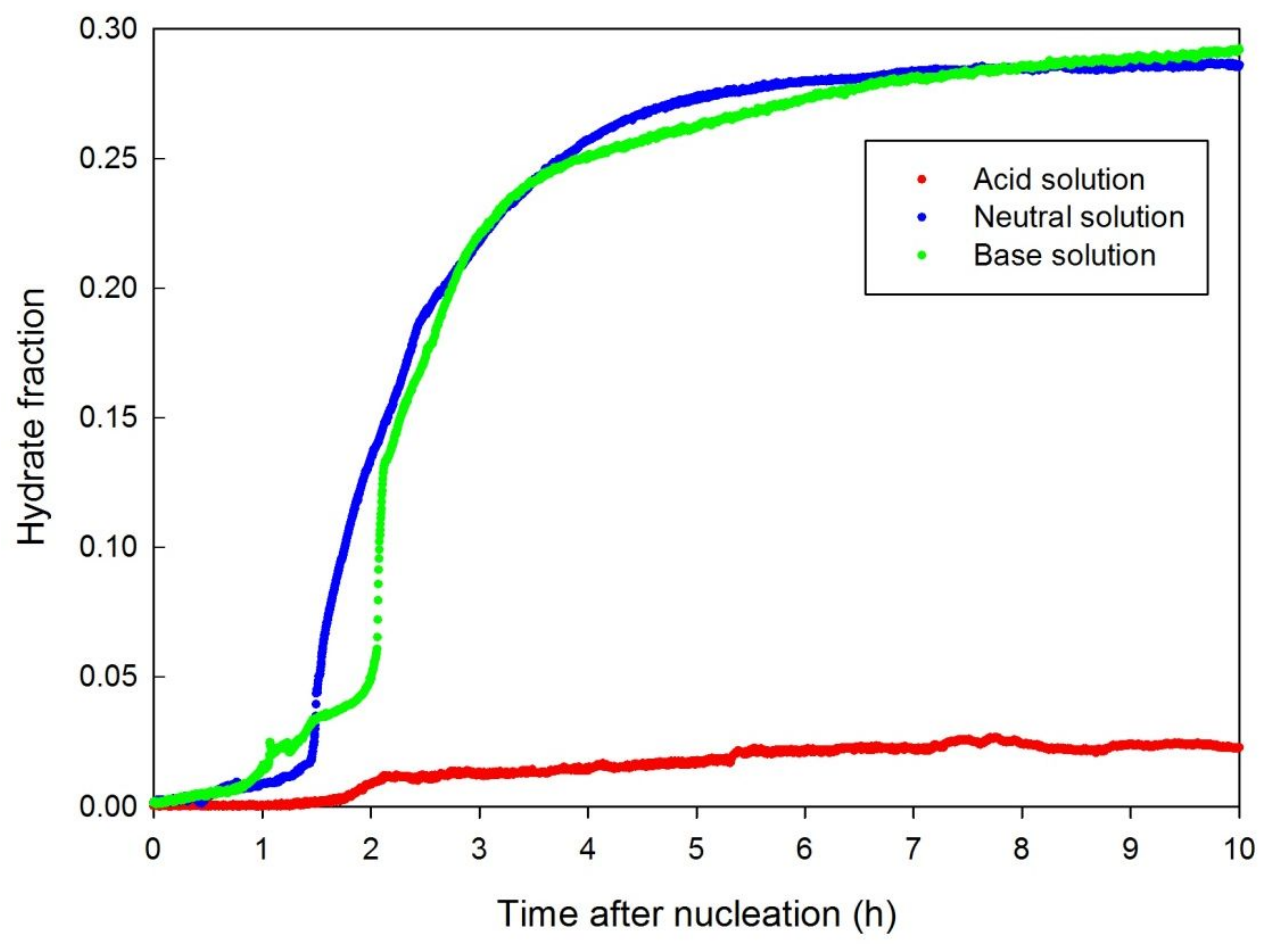

(b)

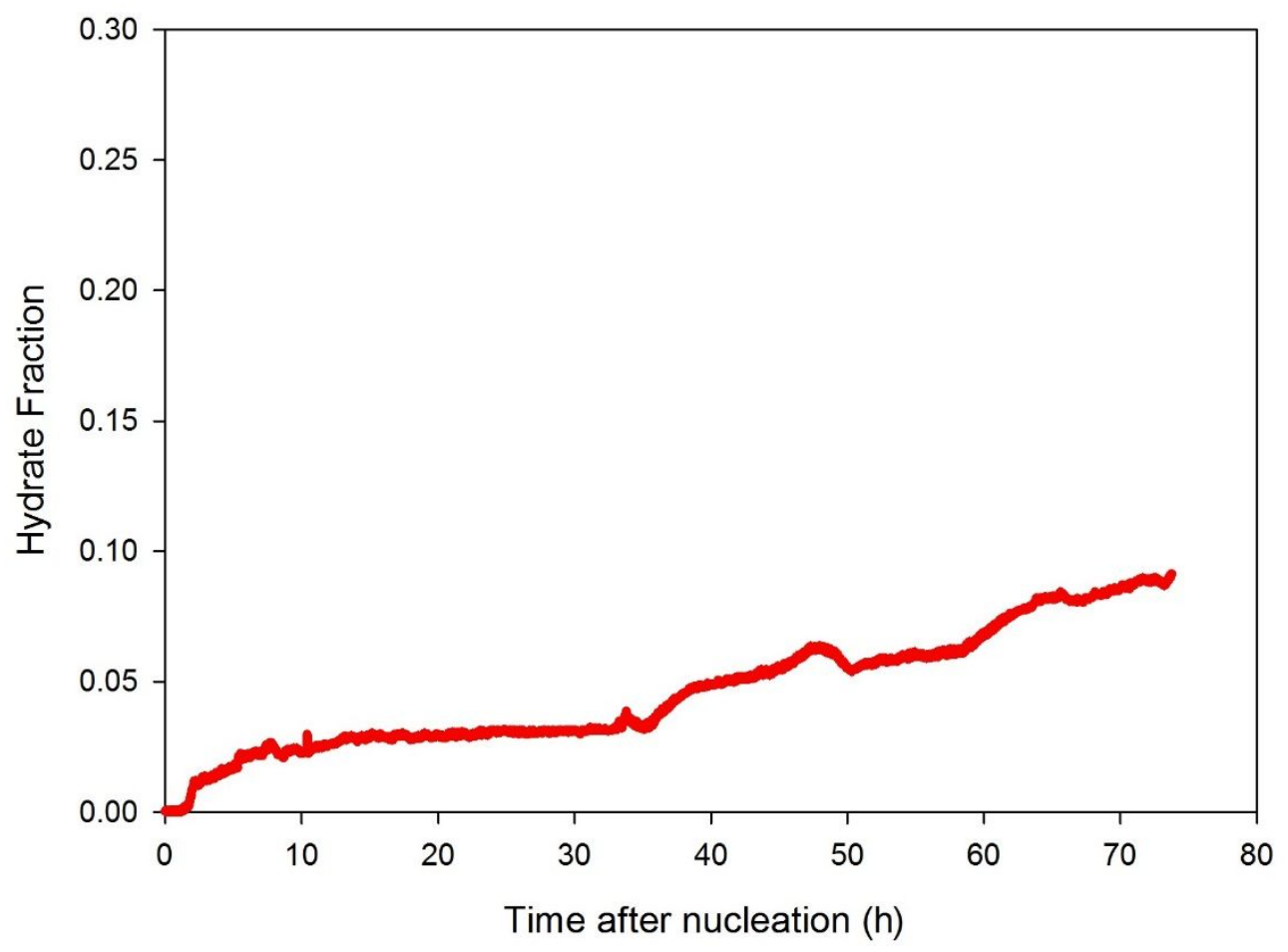

Figure S5: (a) Hydrate fraction curves for MEG $10 \mathrm{wt} \%$ + Luvucap EG $1.0 \mathrm{wt} \%$ solution with $600 \mathrm{rpm}$ at $\mathrm{pH} 4.5,7.0$ and 9.5. (b) hydrate fraction curves at $\mathrm{pH} 4.5$ for 72 hours. 
(a)

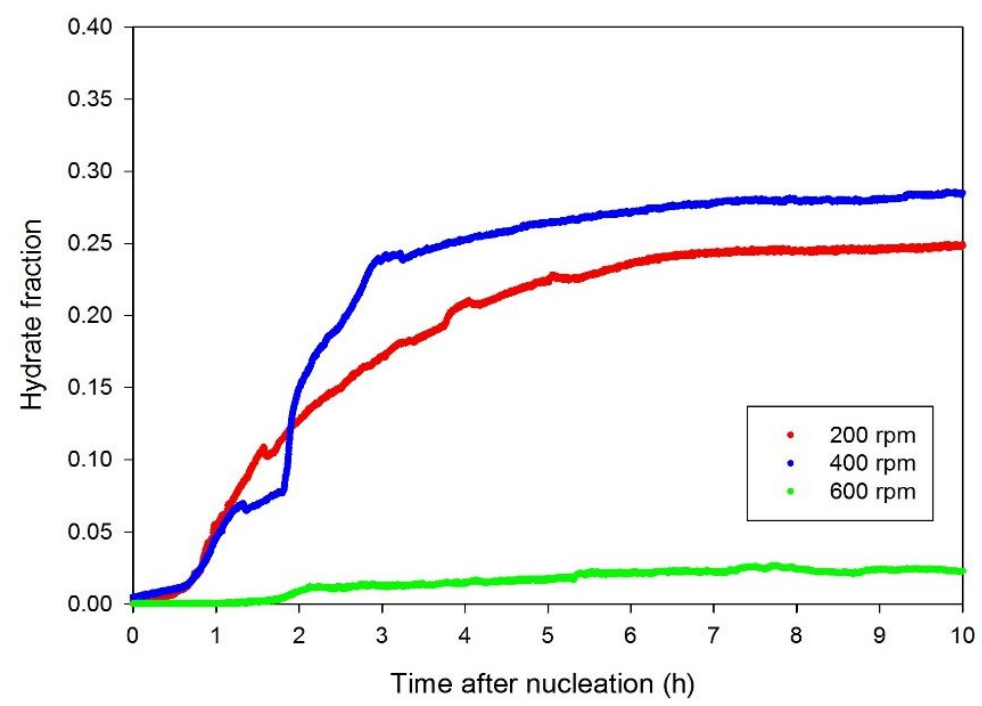

(b)

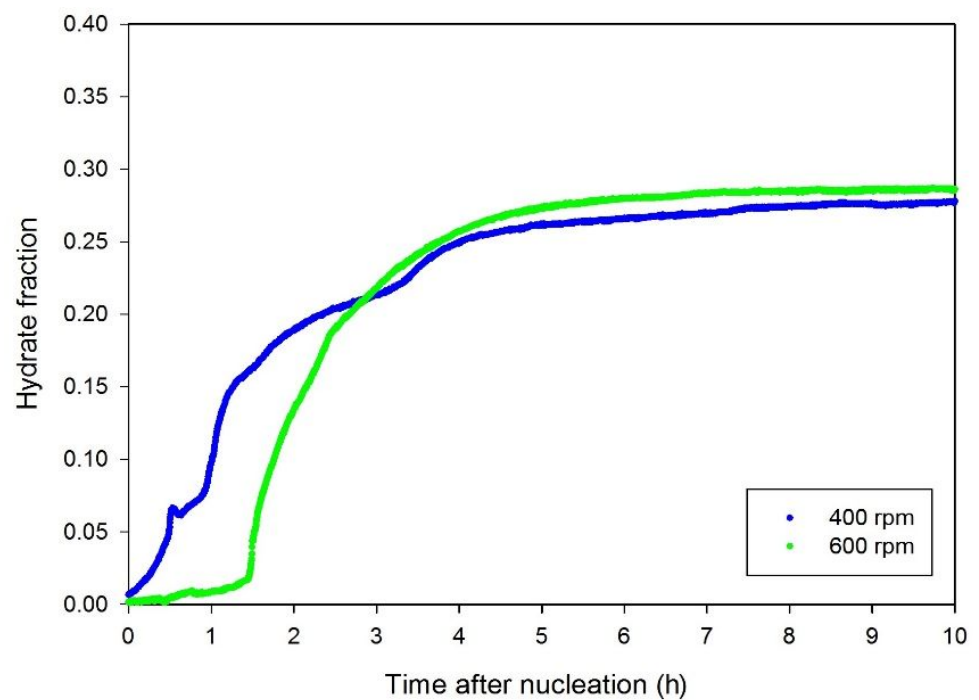

(c)

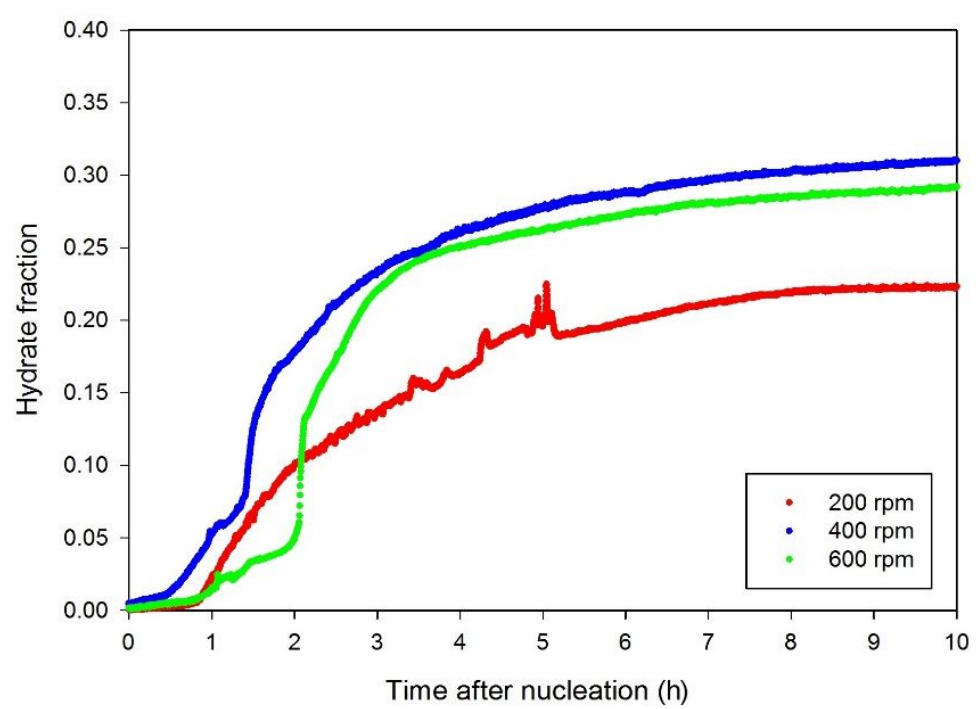

Figure S6: Hydrate fraction curves for MEG $10 \mathrm{wt} \%$ + Luvucap EG $1.0 \mathrm{wt} \%$ solution while varying impeller speeds at $\mathrm{pH}$ conditions (a) 4.5, (b) 7.0 (c) 9.5 . 